\title{
ANATOMY OF THE VAGUS NERVES IN THE REGION OF THE LOWER ESOPHAGUS
} AND THE STOMACH

\author{
RICHARD GENTRY JACKSON, M.D. \\ Departments of Anatomy and Surgery, Dniversity of Michigan, \\ Ann Arbor, Michigan \\ SEVEN FIGURES
}

INTRODUCTION

An anatomic study of the vagus nerves in their thoracic course below the pulmonary plexus, and in their distribution to the stomach has been made in 50 cadavers. Because of the recent increase in interest in the relationship of the vagus nerves to peptic ulcer, the literature was reviewed and revealed relatively few detailed descriptions of the anatomy of the nerves in this area and differences of opinion among anatomists on several points. A study of the nerves seemed desirable, therefore, and in October, 1946, this series of dissections was begun. A preliminary report was published (Jackson, '47) and this is the final report on the complete series of dissections.

The vagus nerves have been described by Swan (1834), Bourgery (1844), Kollman (1860), Perman ('16), Latarjet ('22), and McCrea ('24) who also summarized the literature up to 1925. Reports of dissections of the vagi on the esophagus by Miller and Davis ('47), and of these nerves on the esophagus and the stomach as far as the celiac division of the posterior vagus by Bradley et al. ('47), have recently been published. It may be seen from McCrea's summary that the early anatomists differed principally on the following questions:

1. The number of nerve stems passing through the diaphragm. 
2. The presence of anterior or posterior plexuses on the stomach.

3. Whether or not the posterior trunk is distributed to all or to only a part of the posterior surface of the stomach. Table 1 summarizes the statements of the different anatomists.

Agreement is shown in the following:

1. The anterior gastric vagal trunk and the posterior trunk each contain fibers from both the right and left vagus nerves.

2. Branches leave the anterior trunk just below the diaphragm and pass through the gastrohepatic omentum to the liver.

3. Gastric branches of both the anterior and the posterior trunks are distributed mainly along the lesser curvature of the stomach.

\section{METHODS}

In this study the vagus nerves were first dissected above the diaphragm in 50 cadavers, starting just below the pulmonary plexus and following them to the diaphragm. The specimens used were those being dissected by freshman medical and postgraduate students. In every case the dissection was done before the student reached the area in his dissection, the nerves were charted and, after the heart had been removed and the student was ready for the dissection of the esophageal plexus, they were checked again to be sure that no branches had been missed. After the student had studied the nerves, a number of dissections were photographed to show the disposition of the main trunks and branches. In some instances branches recorded in the original diagram were broken by the students in their examinations and therefore do not appear in the photographs, but do appear in the drawing beside the photograph. The photographs show the size of the trunks and their approximate location on the esophagus. Only the main trunks and divisions, the communicating branches and the larger esophageal branches were charted; the pericardial, the diaphragmatic and the aortic branches 
TABLE 1

The anatomy of the vagus nerves: Points on which anatomists have differed

\begin{tabular}{|c|c|c|c|c|}
\hline & $\begin{array}{l}\text { NUMBER OF } \\
\text { NERVE STEMS } \\
\text { PASSING } \\
\text { THROUGH THF } \\
\text { DIAPHRAGM }\end{array}$ & $\begin{array}{l}\text { PRESENCE OF } \\
\text { PLEXUSES ON } \\
\text { THE STOMACH }\end{array}$ & $\begin{array}{l}\text { SUPPLY TO } \\
\text { PYLORUS } \\
\text { AND } \\
\text { DUODKNUM }\end{array}$ & $\begin{array}{l}\text { DISTRIBUTION } \\
\text { OF POSTERIOR } \\
\text { TRUNK TO } \\
\text { STOMACH }\end{array}$ \\
\hline Swan & $\begin{array}{l}1 \text { anterior } \\
1 \text { posterior }\end{array}$ & $\begin{array}{r}\text { Anterior } \\
\text { present }\end{array}$ & $\begin{array}{l}\text { From hepatic } \\
\text { plexus }\end{array}$ & To cardia \\
\hline Bourgery & $\begin{array}{l}3 \text { anterior } \\
\text { Numerous } \\
\text { posterior }\end{array}$ & No posterior & $\begin{array}{l}\text { From anterior } \\
\text { trunk via } \\
\text { hepatic } \\
\text { plexus }\end{array}$ & $\begin{array}{l}\text { Posterior } \\
\text { aspect along } \\
\text { lesser cur- } \\
\text { vature }\end{array}$ \\
\hline Kollman & $\begin{array}{l}1 \text { anterior } \\
1 \text { posterior }\end{array}$ & $\begin{array}{l}\text { Anterior and } \\
\text { posterior may } \\
\text { be present }\end{array}$ & $\begin{array}{l}\text { From anterior } \\
\text { trunk along } \\
\text { lesser enr- } \\
\text { vature }\end{array}$ & $\begin{array}{l}\text { Only to proxi- } \\
\text { mal portion of } \\
\text { stomach }\end{array}$ \\
\hline Perman & & None & $\begin{array}{l}\text { From anterior } \\
\text { trunk along } \\
\text { lesser cur- } \\
\text { vature }\end{array}$ & \\
\hline Latarjet & & None & $\begin{array}{l}\text { From hepatic } \\
\text { plexus }\end{array}$ & $\begin{array}{l}\text { Posterior } \\
\text { aspect along } \\
\text { lesser cur- } \\
\text { vature }\end{array}$ \\
\hline MeCrea & $\begin{array}{l}\text { 1-2 anterior } \\
1-2 \text { posterior }\end{array}$ & $\begin{array}{l}\text { Both anterior } \\
\text { and posterior } \\
\text { may be present }\end{array}$ & $\begin{array}{l}\text { From hepatie } \\
\text { branch of anterior } \\
\text { trunk, or } \\
\text { separate nerve } \\
\text { through lesser } \\
\text { omentum } \\
\text { (1 case) }\end{array}$ & \\
\hline $\begin{array}{l}\text { Miller, } \\
\text { Davis }\end{array}$ & $\begin{array}{l}\text { 1-3 anterior } \\
\text { 1-2 posterior }\end{array}$ & & & \\
\hline $\begin{array}{l}\text { Bradley, } \\
\text { et al. }\end{array}$ & $\begin{array}{l}\text { 1-several } \\
\text { anterior } \\
\text { 1-several } \\
\text { posterior }\end{array}$ & & & $\begin{array}{l}\text { Not described } \\
\text { in detail }\end{array}$ \\
\hline
\end{tabular}


were not charted. This reduces considerably the apparent complexity of the arrangement of the nerves on the esophagus and makes clearer the course of the trunks destined for viscera below the diaphragm. In the majority of dissections, however, esophageal, pericardial, diaphragmatic and aortic branches were seen, and in one dissection a communicating branch between a sympathetic chain ganglion and the posterior vagus was found.

The following measurements were made:

a. The distance above the diaphragm that the branches from the right and left vagus joined to form single trunks.

b. In some instances the single trunks divided again before passing through the diaphragm. In these instances the distance above the diaphragm at which this division occurred was measured.

\section{DISSECTIONS ABOVE THE DIAPHRAGM}

Four types of anterior and posterior vagal trunks were seen (figs. 1, 2 and 7). Type A became single above the diaphragm and passed through the diaphragm as a single trunk. Type B became single above the diaphragm but divided into two or three trunks before passing through the diaphragm. Type $C$ became single at the diaphragm. Type $D$ was never single above the diaphragm. Forty-seven of the 50 anterior trunks became single at some point between the pulmonary plexus and the diaphragm, two did not become single until they reached the diaphragm, and one was not single at any point. Fourteen of the single trunks divided again before reaching the diaphragm to pass into the abdominal eavity as two or three trunks. Of the 50 posterior trunks, 36 became single at some point between the pulmonary plexus and the diaphragm, 13 became single at the diaphragm, and one was not single at any point. Three of the 36 single trunks divided again into two trunks before passing through the diaphragm.

The average distance above the diaphragm that the anterior trunk became single was $5.13 \mathrm{~cm}$, the posterior trunk 
$3.7 \mathrm{~cm}$. In the 14 anterior and three posterior trunks which divided again before passing through the diaphragm, the point at which they became single averaged $6.67 \mathrm{~cm}$ above the diaphragm for the anterior, $3.8 \mathrm{~cm}$ for the posterior; the point of division averaged $2.46 \mathrm{~cm}$ for the anterior, $2.3 \mathrm{~cm}$ for the posterior. Thus the anterior were single for a longer distance before dividing than the posterior trunks. Of the 100 anterior and posterior trunks, 83 were single trunks at

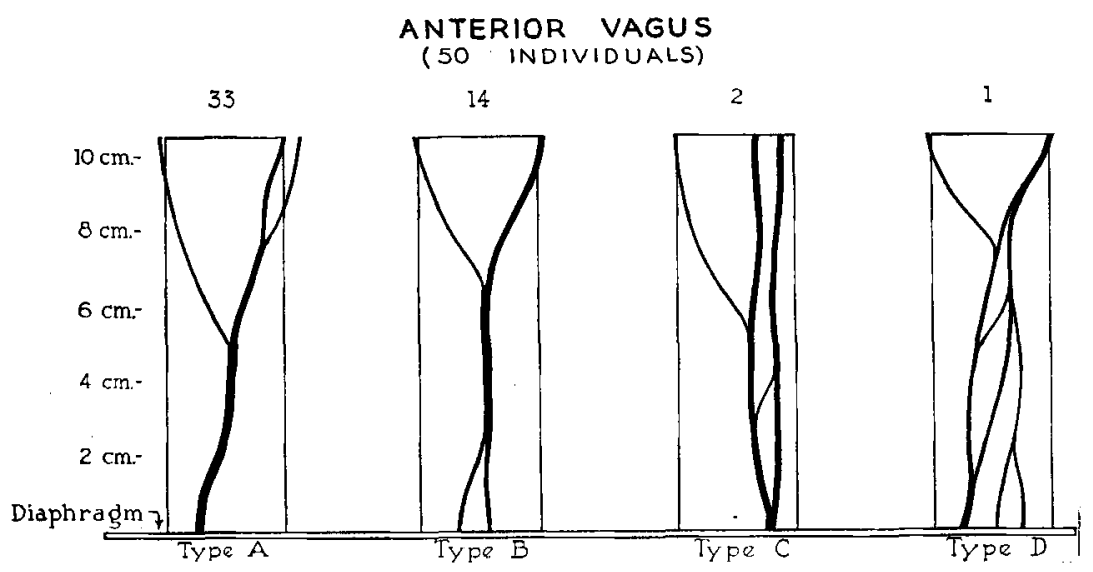

Fig. 1 Formution of anterior vagus by right and left vagus nerves above diaphragm. In Type A single trunks formed above the diaphragm in 33 eases. The average distance above the diaphragm that single trunks appeared was $3.7 \mathrm{~cm}$. Type $B$ became single but divided above the diaphragm. The average distance above the diaphragm they became single was $3.8 \mathrm{~cm}$. The average distance above the diaphragm of the point of division was $2.3 \mathrm{~cm}$. Type $\mathrm{C}$ did not become single trunks until they reached the diaphragm. In Type $D$ single trunks were not formed at any point above the diaphragm.

some point between the pulmonary plexus and the diaphragm,

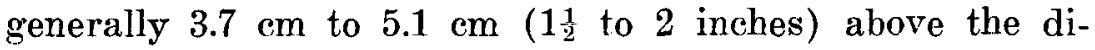
aphragm. Seventeen of these 83 single trunks divided again above the diaphragm. Fifteen of the 100 did not become single until they reached the diaphragm, and two were never single.

The communicating branches were analyzed as follows: Branches passing between the right and left vagus in the inch above the diaphragm were called "low" communicating 
branches; those in the second inch above the diaphragm were called "middle," and those above two inches were called "bigh" communicating branches; those which arose high but did not communicate until the last inch were called "long", communicating branches. Branches from the right to the left always passed anterior to the esophagus, those from the left to the right passed posterior. Communicating branches were not found in all dissections; occasionally more than one anterior

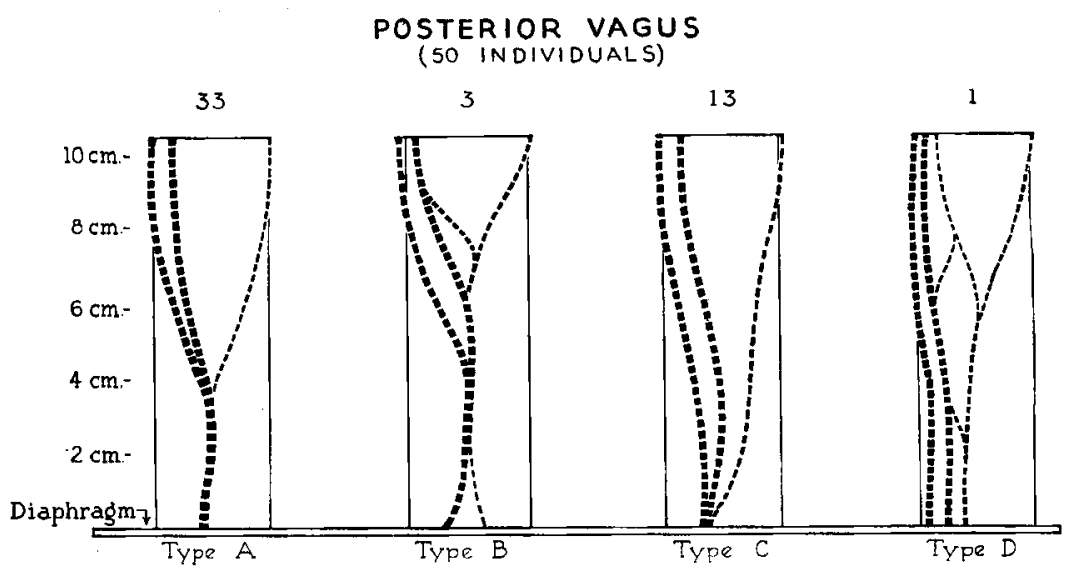

Fig. 2 Formation of posterior vagus by right and left vagus nerves above diaphragm. In type $A$ single trunks formed above diaphragm in 33 cases. The average distaance above the diaphragm that single trumks arose was $5.13 \mathrm{~cm}$. Type $B$ became single but divided above the diaphragm. The average distance above the diaphragm they became single was $6.6 \mathrm{~cm}$. The average distance above the diaphragm of the point of division was $2.46 \mathrm{~cm}$. Type $\mathrm{C}$ did not become single trunks until they reached the diaphragm. In Type D single trunks were not formed at any point above the diaphragm.

or more than one posterior communicating branch were found, and the combinations are recorded in table 2.

In the majority of cases communicating branches were present anteriorly and posteriorly, so that the anterior and posterior trunks which finally pass through the diaphragm represent mixtures of both right and left vagus nerves. The anterior trunk usually became single higher above the diaphragm than the posterior trunk; the corollary of that is the 
fact that the communicating branch or branches from the right to the left vagus were most often of the high type (36 of 50 high or middle or both), whereas those from the left vagus to the right were more frequently the middle or long type ( 37 of 50 middle, long, or both). The relative size of the trunks and branches is shown in the photographs. The posterior vagus was shown by cutting the esophagus at the level of the hilum of the lung and lifting it forward to expose its posterior surface. The captions explain the variations noted. In some specimens the communicating branches ran through the muscular layer of the esophagus.

TABLI 2

Supradiaphragmatic communicaling branches between right and left vagus nerves

\begin{tabular}{lcr}
\hline & ANTHRIOR & POSTERIOR \\
\hline High (see text) & 19 & 7 \\
Middle (see text) & 13 & 20 \\
Low (see text) & 1 & 1 \\
Long & 2 & 15 \\
High, and middle & 4 & 1 \\
High, and long & 1 & 1 \\
Middle, and long & 1 & 1 \\
Middle, long, and low & & 1 \\
None & 9 & 3 \\
& -50 & 50
\end{tabular}

The position of the trunks on the esophagus at the diaphragm with the frequency of occurrence in each location is shown in figure 3.

\section{DISSECTIONS BELOW THE DIAPHRAGM}

In the 50 dissections below the diaphragm, the anterior trunk was picked up by cutting the peritoneum on the esophagus, the trunk was traced downward to locate the gastric branches and these were followed until they disappeared into the gastric wall. The point of origin of the hepatic branch was noted. The posterior trunk was traced, the distribution 
of the gastric branches and point.of origin of the celiac division were traced and the latter was then traced to the celiac plexus. In the first cadaver dissected, the hepatic branch of the anterior trunk was followed to its termination, and an attempt was made to follow the celiac division of the posterior trunk through the celiac plexus. In the remainder of the dissections, attention was concentrated on the gastric branches, the hepatic branch was followed only to the fissure for the ductus venosus, and the celiac division only to the celiac plexus.

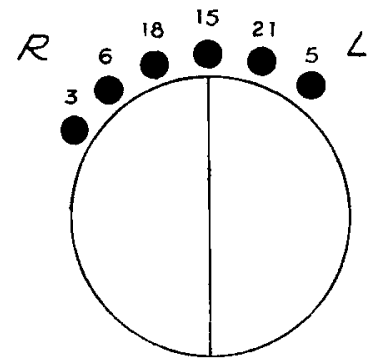

ANTERIOR

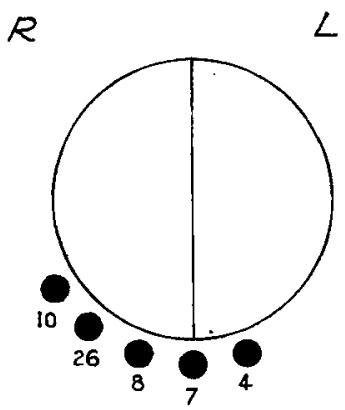

POSTERIOR

Fig. 3 Position of anterior and posterior vagus on the esophagus - viewed from below the diaphragm.

When the hepatic branch of the anterior vagal trunk was followed to its termination (fig. 4), it gave off two hepatic branches at the porta hepatis; it then passed downward on the hepatic artery, gave branches to the plexus on the artery, a branch posteriorly to the pancreas, a branch along the right gastric artery to the region of the pylorus, a branch to the posterior part of the first portion of the duodenum, and a branch along the gastroduodenal artery. This branch continued along the right gastroepiploic artery and, although no branches could be demonstrated passing to the stomach with the branches of the artery, it is thought likely that fine branches did reach the greater curvature in this manner. 
The celiac division of the posterior vagal trunk could not be followed through the celiac plexus. In the dissection shown in figure 5, a branch passed down between the vena cava and the aorta (termination undetermined), and a branch arose

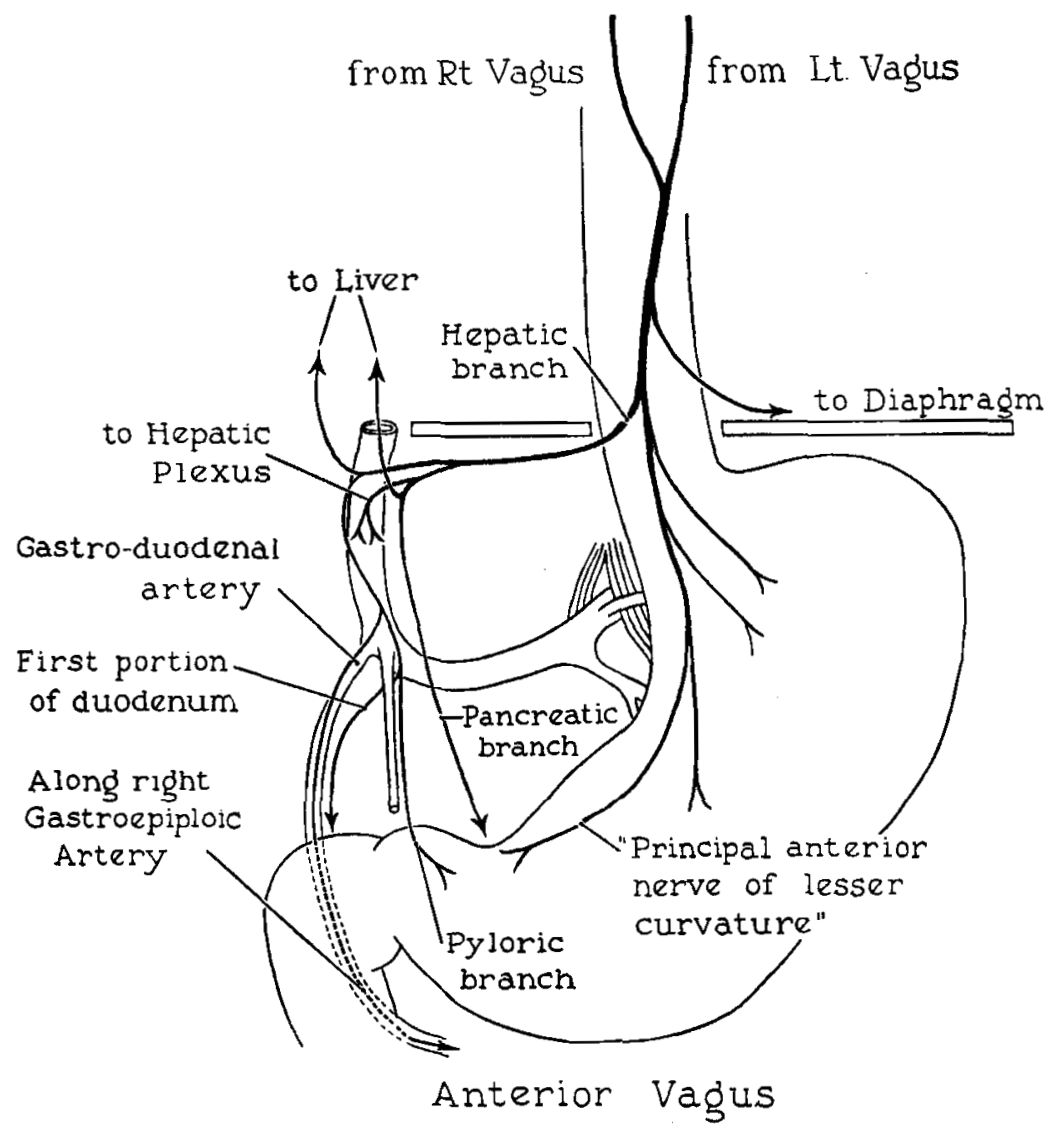

Fig. 4 Dissection of auterior vagus. Distribution of hepatie branch shown.

from the celiac division just before it reached the celiac plexus to pass directly onto the superior mesenteric artery. An hepatic branch arose from the posterior trunk in this specimen; no gastric supply arose from this branch and it communicated with a branch from the celiac plexus. In the 
49 remaining dissections no attempt was made to follow the celiac division through the plexus.

The average number of gastric branches from the anterior trunk was 4, although one to 9 branches were seen. They were distributed to the proximal part of the stomach along

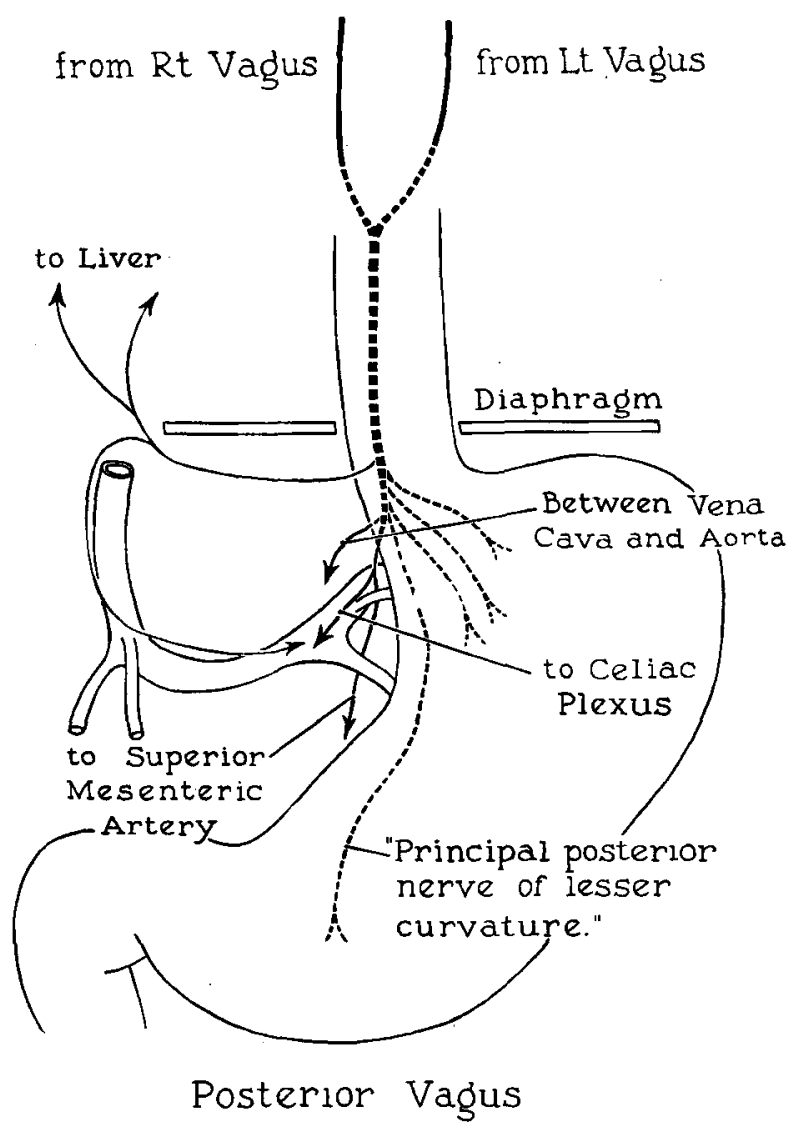

Fig. 5 Posterior vagus. An hepatic branch was found in this dissection.

the lesser curvature, with a branch occasionally almost reaching the greater curvature. In two cadavers no gastric branches were seen; only an hepatic branch was noted. The "principal anterior nerve of the lesser curvature" described by Latarjet was found in 28 instances. This branch some- 
times passed along the lesser curvature, and sometimes passed from the anterior trunk high on the stomach through the lesser omentum near the lesser curvature, usually dorsal to the left gastric artery, returning to the stomach generally from one to three and a half inches from the pylorus. The hepatic branch was seen in all but 7 cases. Two hepatic branches were seen in two cases, and 5 in one case. The hepatic branch left the anterior trunk just below the diaphragm (occasionally just above the diaphragm), and passed through the lesser omentum to run in the fissure for the ductus venosus to the porta hepatis. An anterior plexus was found in two cases.

The anatomy of the posterior vagus is of particular interest. In all cadavers the costal arch and diaphragm were intact, and the liver in place. It became evident that the nerve could be most readily found on the stomach by incising the lesser omentum at the point where the left gastric artery reached the stomach, or if it was not found there, in the triangular area bounded on the right by the right crus of the diaphragm, on the left by the right margin of the stomach, below by the left gastric artery. The variations in the course of the posterior trunk and in the origin of the celiac division were as follows (fig. 6) :

1. In 20 cases the posterior trunk descended along the lesser curvature of the stomach and the celiac division was given off when the trunk reached the left gastric artery and ran along the superior surface of the artery to the celiac plexus.

2. In 14 cases the celiac division arose somewhere between the point at which the left gastric artery reached the stomach and one inch above this point, and ran to the right to reach the left gastric artery.

3. In 9 cases the posterior trunk left the esophagus just below the diaphragm and ran to the right along the crus of the diaphragm, then along the aorta to the celiac plexus, giving off gastric branches along its course.

4. In 5 cases the posterior trunk ran as described in 3 , but gave off a gastric branch late, just before reaching the 
celiac plexus. This branch ran back along the left gastric artery or the coronary vein to the stomach.

5. In one case the celiac division left the posterior trunk just below the diaphragm and extended along the aorta to the celiac plexus, while the gastric portion of the trunk ran down on the stomach.
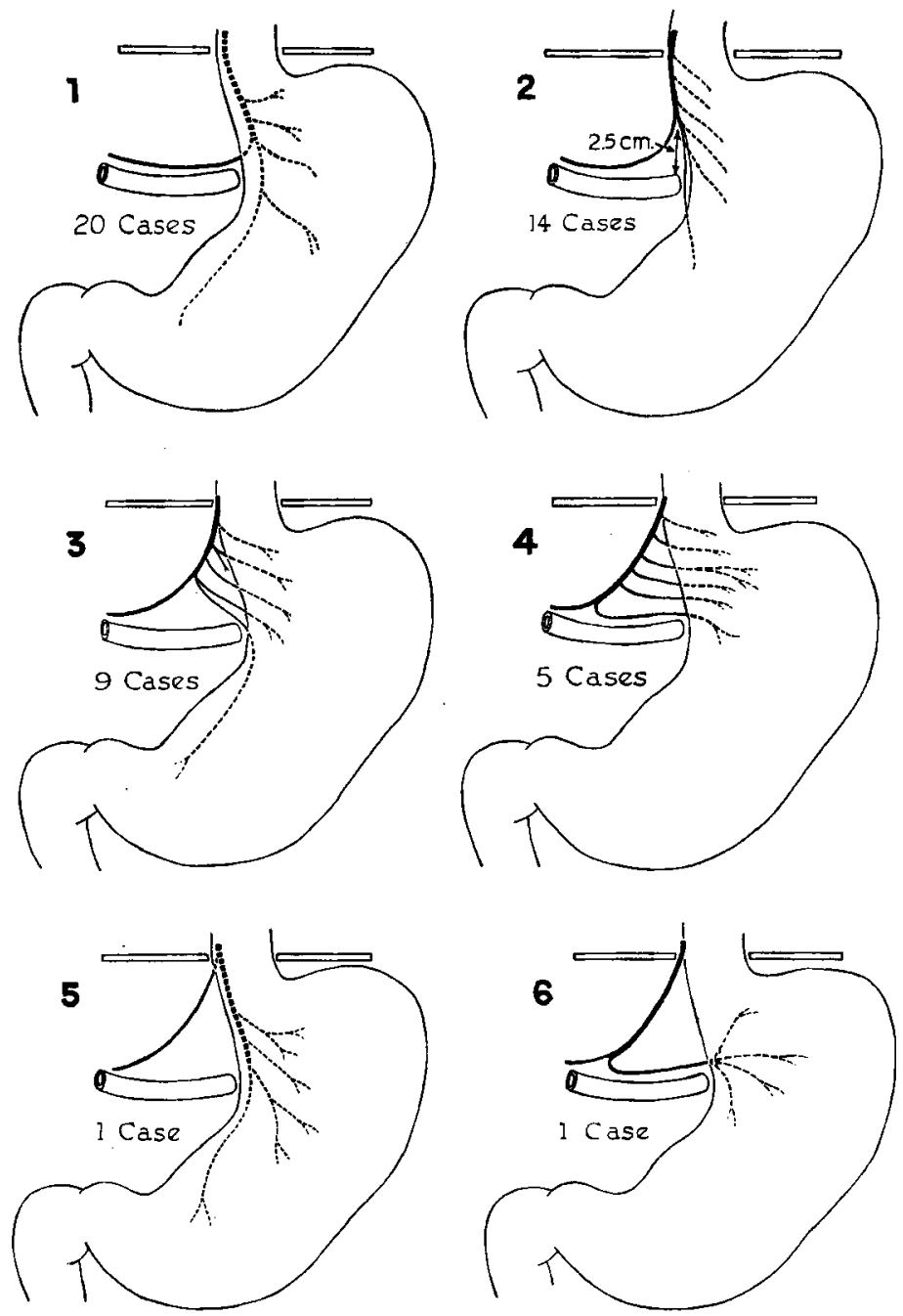

Fig. 6 Variations in course of posterior vagus. 
6. In one case the posterior trunk left the esophagus just below the diaphragm and ran down along the crus, and then along the aorta to the celiac plexus. Just before it reached the plexus, a gastric division emerged to run along the left gastric artery to the stomach where 5 branches passed into the stomach wall.

The average number of gastric branches from the posterior trunk were 6 , although one to 15 were seen, and gastric branches were found in all cases. The "principal posterior nerve of the lesser curvature" described by Latarjet was found in 19 cases. It ran along the lesser curvature toward the pylorus, then turned across the posterior surface of the stomach, usually accompanying a vessel toward the greater curvature, occasionally almost reaching it. No branch, anterior or posterior, reached the duodenum by passing along the stomach. The closest any branch came to the pyloric sphincter region was $2.5 \mathrm{~cm}$. A posterior plexus was found in one dissection.

\section{DISCUSSION}

Section of the vagus nerve supply to the stomach as a treatment of duodenal and of jejunal ulcer has been recently revived and two points are worthy of mention in this connection. The first is a question of terminology. The current surgical literature contains frequent reference to the vagi on the lower esophagus and the stomach as "the anterior or left vagus" and "the posterior or right vagus." Anterior is not synonymous with left and posterior is not synonymous with right in this area; the anterior vagus contains fibers of both the left and right vagi, as does the posterior vagus. Anatomists in the past have stated, and the present dissections confirm the fact, that the left vagus, while it forms most of the anterior vagus, nearly always receives communicating branches from the right vagus, and the right vagus, forming the greater part of the posterior vagus, generally receives branches from the left vagus. When either the left or right 


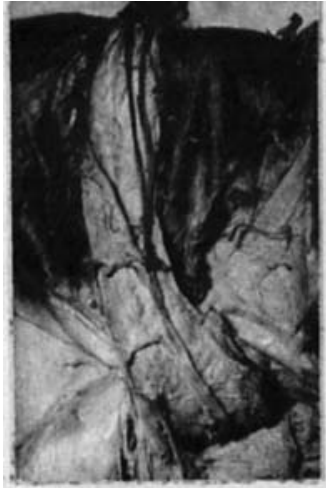

TYPE $A$ (POSTERIOR)

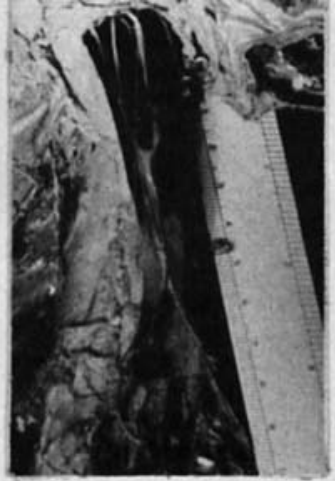

TYPE $B$ (ANTERIOR)

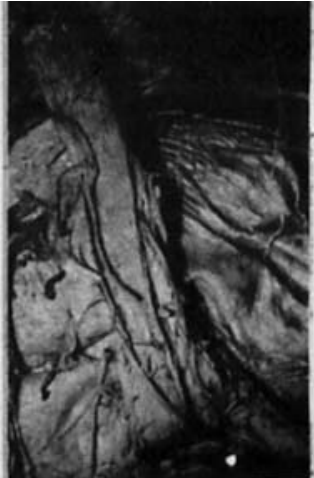

TYPE C (POSTERIOR)

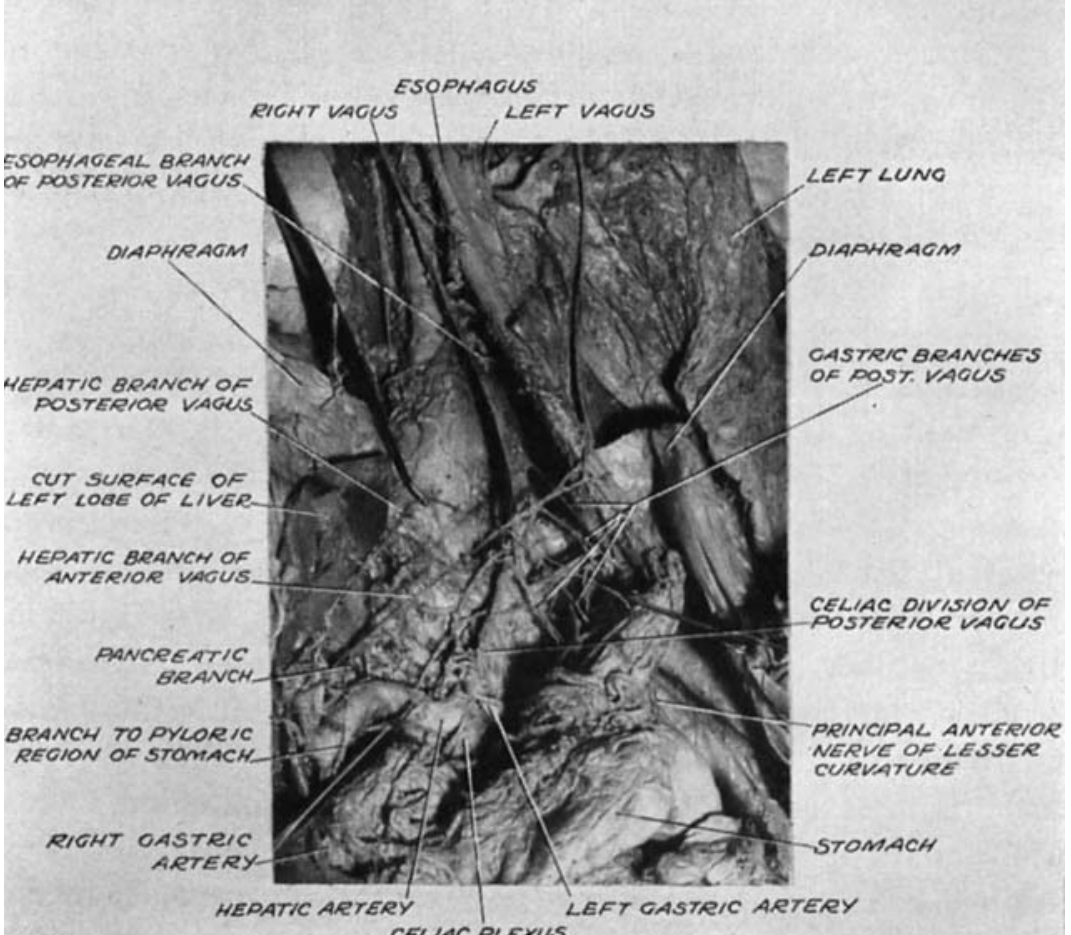

Fig. 7 Dissections of the vagi above the diaphragm in three cadavers and below the diaphragm in a 4 th eadaver are shown. In the supradiaphragmatic dissections, a Type A posterior, a Type $B$ anterior, and a Type $C$ posterior vagus are seen. In the subdiaphragmatic dissection, the hepatic branch of the anterior ragus and the pyloric and pancreatic branches which arise from it, the "principal 


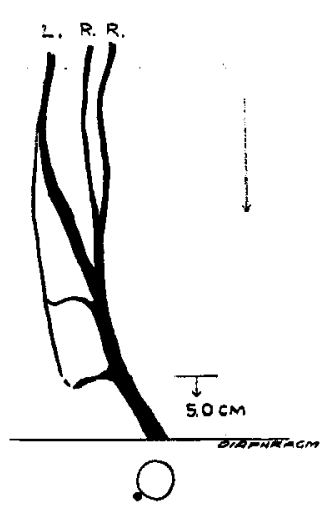

TYPE $A$

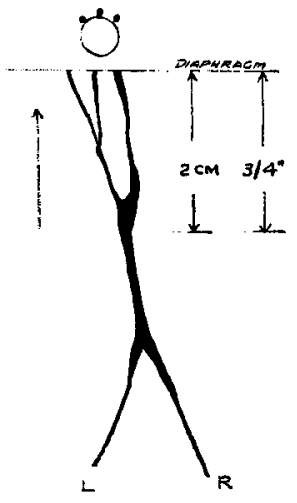

TYPE $B$

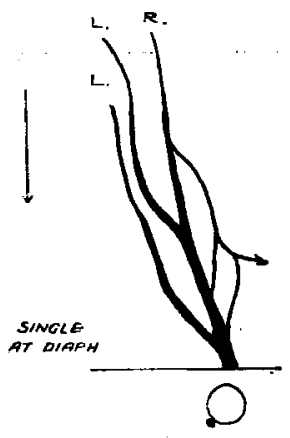

TYPE C C

(POSTERIOR)

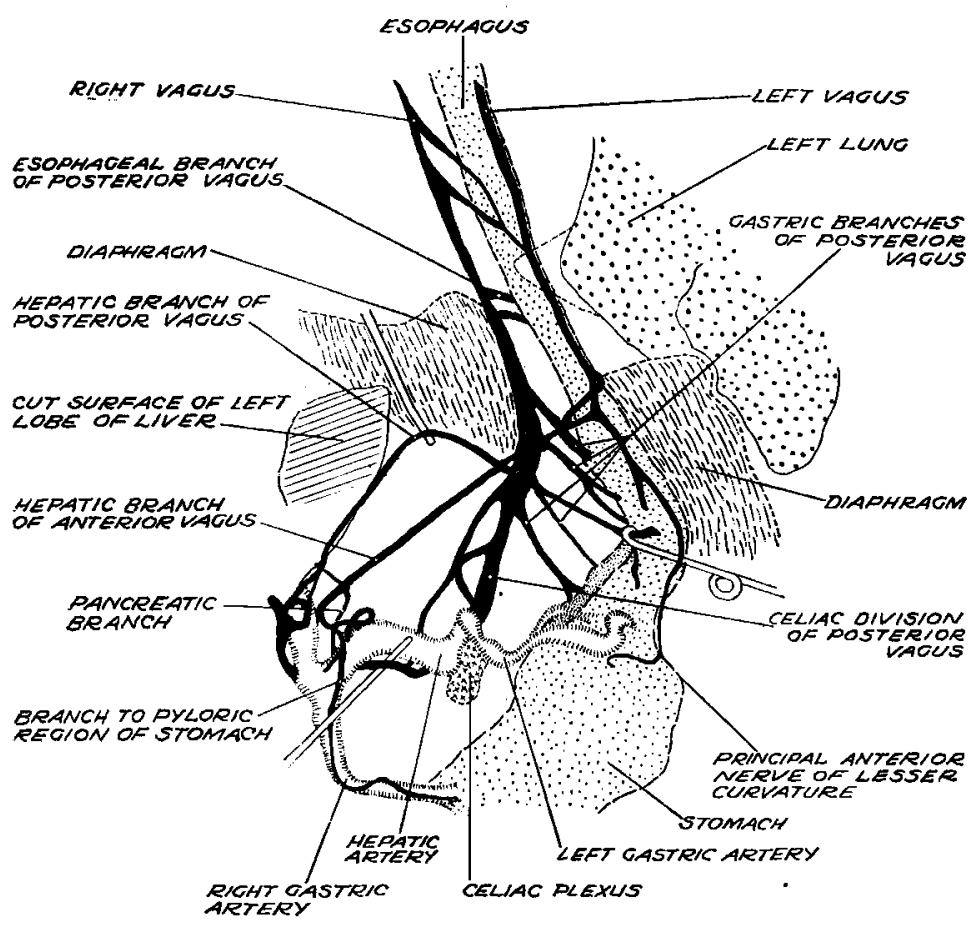

anterior nerve of the lesser curvature" (Latarjet), the hepatic, gastric and celiac branches of the posterior vagus are demongtrated. The line drawings of these dissections include cross sections of the esophagus as seen from below the di. aphragm showing the position of the vagal trunk on the esophagus. 
vagus is cut, the other can supply impulses to both the anterior and posterior surfaces of the stomach. Below the pulmonary plexus the vagus trunks should be called "anterior vagus" and "posterior vagus."

The second point is in reference to branches that might be overlooked. It is more probable that branches of the posterior vagus would be overlooked than branches of the anterior vagus. Above the diaphragm, the frequent occurrence of Type C posterior trunks, in which a single trunk is not formed until the diaphragm is reached, makes it likely that long communicating branches, some of which are small, would be overlooked. Below the diaphragm, the variations in the course of the posterior trunk which have been described again make it possible that a gastric branch might be missed. This is especially true of those posterior trunks which leave the esophagus near the diaphragm and pass to the right, or whose celiac divisions give off gastric branches which return to the stomach. With regard to the anterior vagus, the hepatic branches, particularly those which leave the anterior trunk above the diaphragm and pass through the diaphragm and between the layers of the gastrohepatic omentum near the diaphragm to the liver, might be missed. This hepatic branch is important because from it comes a branch to the pyloric region of the stomach. The Type B trunks of both the anterior and posterior vagus, by dividing above the diaphragm, might cause missed branches if the vagus section were done below the diaphragm and a careful search not made for the several divisions.

\section{SUMMARY}

1. In 50 dissections of the vagus nerves below the pulmonary plexus, the left vagus formed the major portion of the anterior vagus but generally received branches from the right vagus; the right vagus formed the major portion of the posterior vagus, and generally received branches from the left vagus. 
2. Analysis of the esophageal p'exus shows that of the 100 anterior and posterior trunks, 83 became single trunks at some point between the pulmonary plexus and the diaphragm. Seventeen of these 83 trunks divided again to pass through the diaphragm as two or three trunks. Fifteen of the 100 did not become single until they reached the diaphragm, and two were never single.

3. Comparison of the anterior with the posterior trunks shows that the anterior trunks generally become single farther above the diaphragm than do the posterior trunks, and more of the anterior trunks divide again before passing through the diaphragm (28\% of the anterior trunks, $6 \%$ of the posterior trunks). More of the posterior trunks do not become single until they reach the diaphragm ( $26 \%$ of posterior trunks, $4 \%$ of anterior trunks). A greater proportion of the posterior communicating branches are of the "long" type than are the anterior branches.

4. The course, gastric distribution, and hepatic branches of the anterior trunk are described.

5. The variations in course of the posterior vagus and its celiac division are given and its gastric distribution described.

\section{LITERATURE CITED}

Bourgary, M. J. 1844 Traite complet de l'anatomie de l'homme, comprenant la medecine operatoire, avee planches lithographiees d'apres nature par N. H. Jacob. v. 8 plates 42 and 43 . C. A. Delaunay, Paris.

Bradley, W. F., J. T. Small, J. W. Wilson and W. Walters 1947 Gastric neurectomy. J. Am. Med. Assoc., 133: 459-461.

Chamberlin, J. A., and T. Winship 1947 Surgery, 22: 1.

Dragstent, L. R., H. J. Fournier, E. R. Woonward, E. B. Tovee and P. V. Harper 1947 Transabdominal gastrie vagotomy. Surg., Gyn. and Obs., $85: 461-466$.

Doubilei, H., B. G. P. Shapiroff AND J. H. Mvlholland 1948 The anatomy of the periesophageal vagi. Ann. Surg., 127: 128-135.

JACKson, R. G. 1947 Univ. of Michigan Hosp. Bull. 13: 31-35.

Kollman, J. 1860 Leber den Verlauf der Lungeumagennerven in der Bauch. höhle. Ztschr. f. wissensıhl. Zool., 10: 413.

LAtarjet, A. 1922 Resection des nerfs de l'estomac. Teehinque operatoire. Resultats cliniques. Bull. Acad. de med., $8 \gamma^{\prime}: 681-691$. 
MCCREA, E. D. 1924 The abdominal distribution of the vagus. J. Anat., 59: $18-40$.

1926 The nerves of the stomach and their relation to surgery. Brit. J. Surg., 19: 621-648.

Miller, E. M., AND C. B. Davis 1947 An anatomic study of the vagus nerves. J. Am. Med. Assoc., 133 : 461-462.

PeRMan, E. 1916 Utber die Verteilung und den Verlauf der Vagusäste in dem menschlichen Magen. Ark. f. Zool., 10: (no. 11) 1-37.

Swan, J. 1834 A Demonstration of the Nerves of the Human Body. Longman, Rees, Orme, Brown and Green, London. Plates 3, 4 and 7.

Walters, W., H. A. Neibling, W. F. Bradiet, J. T. SMall and J. W. Wilson 1947 Gastrie neurectomy for gastrie and duodenal ulceration. Ann. Surg., $126: 1-18$. 